\title{
A AUTONOMIA dO ALUNO NAS CONCEPÇÕES CLÁSSICA E ILUMINISTA DE EDUCAÇÃO
}

\author{
Samuel Mendonça* \\ Armando Lourenço Filho**
}

\begin{abstract}
RESUMO
Neste artigo, procuramos investigar e discutir a questão da autonomia do educando em dois diferentes momentos históricos: o período clássico e o moderno. O problema do artigo diz respeito à pergunta: Como a questão da autonomia discente foi discutida nos períodos clássico e moderno? Baseamo-nos, sobretudo, nas concepções platônicas acerca da Paidéia e, na concepção educacional pensada por Rousseau e por Kant, no período iluminista, orientada por um novo ideal de formação humana que priorizava o desenvolvimento da razão. Ambas as concepções (clássica e iluminista) apontam para a humanização e para o aperfeiçoamento do homem por meio da educação, destacando, nesse processo, a importância da formação autônoma. $\mathrm{O}$ método diz respeito à revisão bibliográfica por se tratar de exame realizado no contexto da filosofia da educação. Como resultados, pudemos perceber que a autonomia constitui-se de base fundamental para a educação clássica e moderna.
\end{abstract}

Palavras-chave: Autonomia. Paidéia. Iluminismo. Rousseau. Kant.

\begin{abstract}
In this paper we investigate and discuss the autonomy of the student in two different historical periods: the classical and the modern. The problem of the article concerns to the question: how the student autonomy was discussed in classical and modern periods? This study was based mostly on Platonic conceptions about the Paideia, and also in the educational conception thought by Rousseau and Kant, in the Age of Enlightenment, driven by a new ideal of human education that prioritized the development
\end{abstract}

Doutorado em Educação pena Universidade Estadual de Campinas (Unicamp). Coordenador do Programa de Pós-Graduação em Educação da Pontifícia Universidade Católica (PUC Campinas). E-mail: samuelms@gmail.com

${ }^{* *}$ Mestrando em Educação na Pontifícia Universidade Católica (PUC Campinas). Bolsista CAPES. E-mail: professorarmando@hotmail.com 
of reason. Both concepts (classical and modern periods) point out to the improvement of man through the education and also your humanization, highlighting the importance of the autonomous education. The utilized method is the literature review since the subject is within the context of philosophy of education. As a result, we see that autonomy constitutes the fundamental basis for the classical and the modern education.

Keywords: Autonomy. Paideia. Enlightenment. Rousseau. Kant.

\section{Introdução}

A questão da autonomia discente é pauta recorrente em nossos dias, sobretudo porque é vista como essencial para o bom desenvolvimento e aproveitamento do educando nas situações de ensino e aprendizagem. As abordagens pedagógicas, com suas características específicas relacionadas a um dado contexto histórico, social e cultural, podem favorecer ou inibir o desenvolvimento da autonomia dos educandos. Quando há o envolvimento dos alunos de forma espontânea, séria e produtiva, seja na produção do conhecimento ou na própria educação, o exercício da autonomia e os resultados desse processo tendem a ser mais eficientes, tanto para sua formação como indivíduos ou como cidadãos.

$\mathrm{Na}$ sociedade hodierna, percebemos, de fato, a relevância e a importância da discussão do tema da autonomia, dado se tratar de elemento fundamental e anterior a outras questões educacionais, como a aprendizagem, o currículo ou mesmo as políticas públicas. Com efeito, o direcionamento deste artigo se coloca na busca de saber como era pensada a questão da autonomia do educando em dois momentos históricos, a saber: o período clássico e o período moderno. De forma precisa, formulamos a pergunta deste artigo nos seguintes termos: Como a questão da autonomia discente foi discutida nos períodos clássico e moderno? A compreensão da autonomia do aluno ao longo da história do pensamento poderá oferecer ocasião para a necessidade de revisão de como esta temática tem sido pensada na escola atual. Não queremos com isto assumir que a temática da autonomia será exaurida ou mesmo que a nossa investigação signifique resolver os problemas da ausência de autonomia por parte de alguns estudantes. $\mathrm{O}$ pano 
de fundo dessas reflexões está na busca de alternativa para a contínua tarefa de aprimoramento da concepção de educação que temos.

A acepção comum do termo autonomia, segundo Ferreira (2010), refere-se ao termo de origem grega que significa autogoverno, liberdade intelectual, condição que o homem tem de escolher a própria conduta. Já o dicionário de filosofia de Abbagnano (2007) relaciona diretamente o termo aos estudos do filósofo alemão Immanuel Kant, que, por sua vez, estabelece um paralelo a este conceito explicando a necessidade e a importância do esclarecimento (Aufklärung), que compreende a "saída do homem de sua menoridade, pela qual ele próprio é responsável. A menoridade é a incapacidade de se servir de seu próprio entendimento sem a tutela de um outro" (KANT, 2008, p. 11). A acepção kantiana de maioridade significa, portanto, a possibilidade do homem fazer uso de seu esclarecimento, isto é, assumir a sua liberdade por meio da razão. Cabe explicitar que a acepção kantiana de autonomia se justifica no ideal iluminista de homem do século XVIII e que é preciso o devido cuidado para a compreensão desta acepção na atualidade, em especial no Brasil, País marcado pela exploração desde a sua descoberta (SAVIANI, 2008).

Esclarecimento seria então a capacidade de utilização do entendimento, da razão em favor próprio, sem a dependência de outras pessoas, ou, como o filósofo explica, sem a necessidade de se recorrer a terceiros, o que caracteriza o pensar por si mesmo e o exercício da liberdade de pensamentos e atitudes, elementos fundamentais para a construção da autonomia. Com o devido cuidado com as variáveis que marcam a Alemanha do século XVIII e o Brasil na atualidade, temos como meta desenvolver o conceito de autonomia discente a partir da orientação iluminista de homem. Liberdade intelectual, capacidade para tomar suas próprias decisões com consciência e responsabilidade, enfim, o elemento chave que faz a ligação entre o mundo da teoria presente na sala de aula e o da vida concreta e prática do cotidiano, independentemente do momento histórico ou condição social em que se insere o sujeito educando.

Do ponto de vista formal, iniciamos nossas reflexões em torno da autonomia pelo classicismo, com as concepções platônicas de educação acerca do ideal educacional grego, a Paidéia, e pelo período iluminista, com a concepção de um novo ideal de formação humana, baseado 
na concepção educacional pensada por Rousseau (1968) e por Kant (2008, 1996). Ambas as concepções apontam para a humanização e para o aperfeiçoamento do homem por meio da educação, destacando a importância da formação autônoma. Na Grécia, notamos uma perspectiva mais voltada para a formação do governante, do filósofo, do pensador e, na concepção iluminista, uma perspectiva mais humanista, visualizando no desenvolvimento da razão a possibilidade do homem atingir seu potencial natural, seja para suas aptidões individuais ou coletivas, de cidadão.

\section{A autonomia do aluno na Antiguidade Clássica - o conceito de Paidéia}

Nossa trajetória pela história da educação à procura de indícios sobre o desenvolvimento da autonomia dos educandos inicia-se na Antiguidade Clássica. Na Grécia antiga, elaborou-se o projeto educacional mais avançado do período Clássico. Braga afirma que esse projeto "visava à 'construção' do Homem em todas as suas dimensões. A partir desse Homem seria possível lançar as bases de uma nova civilização" (BRAGA, 2000, p. 40) voltada para uma nova configuração social em torno da polis.

Essa nova proposta de formação educacional, a Paidéia, tornouse até os dias de hoje grande fonte de inspiração àqueles que tencionam discutir temas relacionados à educação, sobretudo, relacionando-os aos contextos da história do pensamento educacional e à filosofia da educação. É praticamente impossível falar em Paidéia sem mencionar a homônima obra do professor e historiador alemão do século XIX, Werner Jaeger.

Jaeger declara que foram os gregos quem estabeleceram "pela primeira vez de modo consciente um ideal de cultura como princípio formativo" (JAEGER, 1994, p. 8), segundo o qual se procurava, na semelhança de um artista diante da sua obra, moldar e forjar o corpo, a mentalidade e o caráter dos educandos, com vistas a um ideal sublime de formação humana.

De acordo com Jaeger, o conceito de Paidéia está relacionado à totalidade da formação do homem grego, em suas particularidades físicas, sociais e históricas, assim, "não se trata de um conjunto de idéias abstratas, mas da própria história da Grécia" (JAEGER, 1994, p. 7). A Paidéia trata da 
criação de um novo ideal, mais elevado, de ser humano. Jaeger ainda afirma, quanto aos gregos, que "a mais alta obra de arte que o seu anelo se propôs foi a criação do Homem vivo. Os Gregos viram pela primeira vez que a educação tem de ser também um processo de construção consciente" (JAEGER, 1994, p. 13), organizado e programado com vistas a uma finalidade específica, por isso a necessidade desse retorno à Grécia e à sua cultura.

$\mathrm{Na}$ busca por subsídios para uma melhor fundamentação educacional, muitos autores recorrem ao modelo grego com o objetivo de destacar alguns elementos históricos e filosóficos que podem vir a embasar seus pensamentos acerca da temática educacional e, desta forma, várias definições foram propostas na direção de retratar da melhor forma possível um conceito tão rico e abrangente.

Para Gadotti, o conceito de Paidéia era o de "uma educação integral, que consistia na integração entre a cultura da sociedade (...) uma pedagogia da eficiência individual e, concomitantemente, da liberdade e da convivência social e política" (GADOTTI, 2002, p. 30). Esta educação integral cuidava do corpo, da mente e da moral, sendo composta pela ginástica, pela filosofia e pelas artes consecutivamente (GADOTTI, 2002). Braga afirma que:

A paidéia grega pretendia mais que educar, visava formar os Homens. Formar era, acima de tudo, dar forma a um novo ser espiritual. $O$ formar ultrapassa a idéia de transmissão de conhecimentos acumulados pela tradição coletiva ou relativos às aptidões profissionais. Na formação a utilidade imediata do saber não é um objetivo essencial (BRAGA, 2000, p. 40).

Nesse contexto, duas cidades se destacavam na formulação desses novos ideais educacionais gregos, cada qual com suas características específicas, mas ambas influenciando diretamente na concepção cultural da nação: Esparta e Atenas, esta última herdeira da tradição jônica, que por sua vez trazia uma concepção de Paidéia mais relacionada à formação do cidadão, sendo centrada no indivíduo e não no Estado (BRAGA, 2000).

O historiador francês Henri-Irénée Marrou afirma que Esparta era uma cidade predominantemente militar, com características aristocráticas, 
conservadoras e reacionárias, possuindo uma população de semiiletrados, pois, "a educação do jovem espartano era (...) uma educação precipuamente militar, um aprendizado direto e indireto do ofício das armas" (MARROU, 1975, p. 35), inserida num plano político, onde se cultivava o ideal coletivo da polis caracterizado pela total devoção ao Estado. Este ideal formativo "subordina a pessoa humana à coletividade política: a educação espartana (...) não terá mais por fim selecionar heróis, mas formar uma cidade inteira de heróis - soldados prontos a se devotarem à pátria" (MARROU, 1975, p. 36).

Por outro lado, em Atenas, o estilo de vida era outro. As pessoas já não precisavam mais portar as suas couraças e espadas e, a educação física, por exemplo, embora ainda recebesse um lugar de honra, não configurava mais o culto ao corpo proveniente do modelo espartano e, além disso, também se esforçava para desvincular-se das características predominantemente militares que possuía (MARROU, 1975). A educação tornara-se civil. Gadotti acrescenta que "entre os espartanos predominava a ginástica e a educação moral, esta submetida ao poder do Estado; já os atenienses, embora dessem enorme valor ao esporte, insistiam mais na preparação teórica para o exercício da política" (GADOTTI, 2002, p. 30).

Segundo Marrou, em Atenas, cada vez mais desaparece a ênfase sobre o aspecto militar da vida dos cidadãos, sendo destacados então outros valores, mais intelectuais, como a construção das virtudes civis da vida política. Figura marcante entre os principais expoentes da educação ateniense, Platão "deslustra formalmente o ideal guerreiro da antiga educação espartana” (MARROU, 1975, p. 109), instruindo seus discípulos a partir de um novo ideal, de sabedoria, baseado no "aspecto moral da educação, da formação pessoal, da vida interior” (MARROU, 1975, p. 105). Platão prefigura assim, essa nova característica do cidadão ateniense, mais filosófico e menos guerreiro.

Diferenças à parte, as duas cidades rivais acabaram mutuamente colaborando para a construção do ideal educacional grego. Esparta, valorizando a importância da cidade para a comunidade, destacando, além disso, os aspectos morais e a responsabilidade do cidadão e, Atenas, sob um aspecto mais teórico, relacionado, sobretudo, à formação do homem político como um sinônimo do homem social. 
Para Jaeger, "a importância universal dos Gregos como educadores deriva da sua nova concepção do lugar do indivíduo na sociedade" (JAEGER, 1994, p. 9), que passa a ser valorizado pelo seu engajamento político e participação ativa nas decisões pertinentes à vida coletiva nas cidades, assim, "a essência da educação consiste na modelagem dos indivíduos pela norma da comunidade" (JAEGER, 1994, p. 15). Nesse sentido, vale afirmar que, conforme a visão platônica, na qual Sócrates ${ }^{1}$ está inserido, o objetivo principal da educação grega era a formação política do homem, a construção do futuro governante.

Conforme declara Jaeger, "a premissa fundamental da qual Sócrates parte (...) é a de que toda educação deve ser política. Tem necessariamente de educar o Homem para uma de duas coisas: para governar ou ser governado" (JAEGER, 1994, p. 546). Sócrates propõe uma educação baseada em uma formação política, que prepara o cidadão para ser um bom governante da sua cidade, da sua casa, enfim, da sua própria vida, em outros termos, governar-se a si mesmo, exercer a autonomia.

Observamos desta forma, que, já no período Clássico, a autonomia se apresenta como base da formação educacional do futuro legislador. Entretanto, é importante esclarecer que a autonomia, neste período, não tem acepção popular, dado que a educação Clássica é estritamente aristocrática. Em que pese o fato de que a nossa preocupação é dada em relação à promoção da autonomia dos alunos, ainda assim, pensamos que a visão grega sobre a acepção de autonomia diz respeito ao nosso interesse neste momento. Não poderíamos deixar de questionar a educação elitizada deste período e, portanto, de certa maneira, guardadas as diferenças para a sociedade hodierna, o sistema da educação de massas que temos hoje parece ter suas raízes na Grécia antiga.

1 Um estudo rigoroso das conexões entre o pensamento de Sócrates e a educação foi publicado recentemente por Kohan (2011). Embora o autor não tenha desenvolvido o tema da autonomia em Sócrates, de forma específica, o segundo capítulo intitulado Foucault e o cuidado de Sócrates evidencia os vínculos da análise do filósofo francês em torno do cuidado de si e dos outros que remete, em última instância, ao ideal grego de autonomia; afinal, a educação do homem grego tem duas características fundamentais: governar e ser governado. 
Prosseguindo nossa investigação, destacamos que, para uma maior compreensão dos ideais educacionais socráticos, é necessário analisar, ainda que de forma incipiente, a abordagem sofista. Segundo Jaeger, "os sofistas foram considerados os fundadores da ciência da educação. Com efeito, estabeleceram os fundamentos da pedagogia e ainda hoje a formação intelectual trilha, em grande parte, os mesmos caminhos" (JAEGER, 1994, p. 348). Eram dotados de prestígio e status especiais, muito valorizados e requisitados por aqueles que tinham como objetivo se instruir (JAEGER, 1994). Complementando esse panorama, Morandi afirma que os sofistas eram "educadores profissionais, voltados para o ensino da arte de moldar bons cidadãos, da arte da política" (MORANDI, 2008, p. 35). No entanto, precisamos observar que eles apresentavam-se como mestres ambulantes, forasteiros e ensinavam uns poucos privilegiados, filhos de cidadãos abastados, mediante boas retribuições em dinheiro (JAEGER, 1994).

Braga (2000), por sua vez, afirma que a educação sofista tinha como objetivo o aperfeiçoamento do homem, para isso, partia da formação enciclopédica centrada no conhecimento geral das coisas e da formação espiritual, baseada na música, na poesia, na gramática e na retórica, como forças que contribuíam para a formação da alma.

Segundo Jaeger, Sócrates não negava o valor dessa educação, pelo contrário, reconhecia a sua abrangência e importância, a ponto de negar o ensino sobre as matérias que não dominava e "procurar frequentemente o mestre adequado para aqueles que a ele acorriam ávidos de se instruírem em tais conhecimentos" (JAEGER, 1994, p. 544). No entanto, devemos notar o cuidado de Jaeger, em sua escrita, ao qualificar o mestre como 'adequado', denotando dessa maneira tanto o zelo com que Sócrates abordava a questão educacional, quanto o fato de que poderiam existir também os mestres não adequados, ou inapropriados. Nesse sentido, compreendemos, quanto a Sócrates, segundo a análise de Jaeger, porque "o seu apelo ao cuidado da alma continha já potencialmente um critério de limitação dos conhecimentos recomendados por aqueles educadores" (JAEGER, 1994, p. 538), pois muitas vezes se posicionavam contraditoriamente às verdades que acreditava e ensinava. Jaeger (1994) afirma que o objetivo do ensino sofista era a disciplina do espírito, entretanto, cada educador possuía suas próprias convicções sobre como 
alcançá-la, defendendo cada qual o seu próprio método, considerando-o mais eficiente que as demais. Nessa disputa declarada pelos aprendizes, cada professor procurava sobrepujar-se ao seu adversário, muitas vezes pondo em alerta seus valores éticos e morais.

Após a leitura de $A$ apologia de Sócrates (PLATÃO, 1999) percebemos que, para Sócrates, a educação era vista como instrumento de libertação do homem, algo que dignificava e atribuía valores éticos e morais ao ser humano. A arte de lecionar deveria, portanto, ser considerada uma honra, digna de poucos, e, aqueles que possuíssem tal capacidade, deveriam ser, antes de tudo, homens de caráter, mestres que apresentem tanto virtudes de homem como de cidadão.

Sócrates ainda se orgulhava de não ganhar dinheiro lecionando. Abertamente criticava os sofistas que assim agiam, ironizando-os, pondo em dúvida suas qualidades educacionais e, sobretudo, as morais (PLATÃO, 1999). Os ensinamentos socráticos, muito mais voltados para os cuidados da alma, divergiam em muito da disposição cultural de sua época, que privilegiava o ter em detrimento ao ser, assim, descreve sua missão:

Nada mais faço a não ser andar por aí convencendo-vos, jovens e velhos, a não cuidar com tanto afinco do corpo e das riquezas, como de melhorar o mais possível a alma, dizendo-vos que dos haveres não provém a virtude para os homens, mas da virtude provêm os haveres e todos os outros bens particulares e públicos (PLATÃO, 1999, p. 57).

Como vemos neste trecho, Sócrates incita um pensamento sobre a origem das virtudes e dos haveres e bens materiais. Afirma que as riquezas não promovem as virtudes individuais, antes, das virtudes é que se provêm os haveres. Como já dissemos, os sofistas eram educadores profissionais, bem remunerados por sua profissão. No entanto, será que os educadores sofistas tinham real compromisso com a verdade? Ou eles simplesmente vendiam conhecimentos para quem oferecesse mais dinheiro? E sobre esses ensinamentos, qual seria a sua qualidade, o seu compromisso com a verdade? Não queremos aqui desqualificar o trabalho educacional realizado pelos sofistas, entretanto, devemos ponderar sobre as considerações apresentadas por Sócrates, a fim de compormos uma visão contextualizada 
daquela época e, neste sentido, o desenvolvimento das virtudes simboliza o que havia de mais importante para o ideal de homem grego.

März afirma que "Sócrates, a semelhança dos seus grandes adversários, os sofistas, preocupava-se com o esclarecimento. Não um esclarecimento superficial, popular, barato, mas desmascarante, que mostrava ao esclarecido a sua própria ignorância" (MÄRZ, 1987, p. 1). Nesse sentido, percebemos que Sócrates procurava instruir seus espectadores a julgar toda informação que daqueles se ouvia, pois, como não confiava nas suas intenções, de maneira irônica os procurava desvelar:

Não obstante, acho bonito ser capaz de ensinar, como Górgias de Leontinos, Pródico de Ceos e Hípias de Eléia. Cada um deles, senhores, é capaz de ir de cidade em cidade, convencendo os jovens, que podem freqüentar um de seus concidadãos à sua escolha e de graça, a deixarem essa companhia e virem para a sua, pagando e ainda ficando-lhes agradecidos (PLATÃO, 1999, p. 43).

Nesse trecho, Sócrates fala dos cidadãos que poderiam aprender de graça, com um professor já conhecido de sua região, um concidadão, mas acabam sendo convencidos pelos sofistas, vindos de outras cidades, a serem seus discípulos, pagando caro por isso e ainda ficando agradecidos por receberem essa educação que, para ele, se mostrava um tanto duvidosa. O que nos intriga nesse contexto é: Como seria a abordagem desses sofistas? Como eles se dirigiam ao povo? O que será que eles prometiam ou ofereciam para convencer essa gente a segui-los? O que eles diziam sobre os outros educadores? Pensamos que estas sejam indagações pertinentes, mas, ainda mais relevante é saber como o povo via esses educadores estrangeiros, na verdade, ainda mais profundo que isso, como o povo via o conhecimento e a instrução por eles ministrada? Afinal, será que esses cidadãos conseguiam compreender o teor de seus ensinamentos, será que eles tinham autonomia intelectual suficiente para discernirem o que é bom daquilo que não é?

Braga afirma que "enquanto a sofística buscava ensinar a techné política, Sócrates perguntava o porquê de tudo isso" (BRAGA, 2000, p. 46). Segundo Morandi, para Sócrates, "educar para a verdade não diz respeito à 
instrução; ensinar é interrogar²; não dar um saber, mas permitir o acesso ao questionamento, estabelecer um caminho da verdade, delegando ao aluno a revelação do saber, objeto da pesquisa comum" (MORANDI, 2008, p. 37). Educar é, nesse sentido, levar o aluno à construção, ou melhor, à reconstrução pessoal do conhecimento pelos seus próprios caminhos, pela sua própria experiência. Ao aluno cabe a busca e a descoberta, o esforço e a recompensa pela conquista ${ }^{3}$.

Era justamente a isso que Sócrates se propunha. Jaeger afirma que Sócrates era um cidadão comum, conhecido por todos, falava aos seus ouvintes sobre qualquer assunto, mas "não se dedica ao ensino nem tem discípulos, assim o afirma, pelo menos. Só tem amigos, camaradas" (JAEGER, 1994, p. 523).

Podemos verificar a afirmação de Jaeger analisando o trecho abaixo, dito por Sócrates e transcrito por Platão:

Jamais fui mestre de ninguém, embora nunca me opusesse a jovem ou velho que desejasse me ouvir na execução da minha tarefa. Tampouco falo se me pagam, e se não pagam, não; estou da mesma maneira à disposição do rico e do pobre, para que me interroguem ou, se preferirem ser interrogados, para que ouçam o que digo. Se algum deles se torna honesto ou não, não é justo que eu seja responsabilizado pelo que nunca prometi nem ensinei a ninguém. Quem afirmar que de mim aprendeu ou ouviu em particular alguma coisa que não todos os demais, tenhais certeza de que falta com a verdade (PLATÃO, 1999, p. 61).

\footnotetext{
2 Esse método de ensino, baseado em um direcionamento a partir dos questionamentos diretos, é conhecido por Maiêutica Socrática. Maiêutica: "Na filosofia socrática, arte de extrair do interlocutor, por meio de perguntas, as verdades do objeto em questão" (FERREIRA, 2010, p. 481). Segundo Abbagnano, "Sócrates compara seus ensinamentos a essa arte, porquanto consistem em dar à luz conhecimentos que se formam na mente de seus discípulos" (ABBAGNANO, 1997, p. 637).

3 Esta perspectiva educacional é, antes de qualquer coisa, filosófica. A arte de perguntar evidencia a preocupação com a busca do conhecimento e não com sua posse, e, de certo modo, a dimensão da autonomia a que problematizamos neste trabalho abarca esta perspectiva na medida em que, no horizonte, o aluno autônomo deverá desenvolver a atitude filosófica.
} 
Sócrates, em sua fala acima citada, posiciona-se com relação à remuneração destinada aos professores, mas também deixa transparecer o caráter social que atribuía à educação, demonstrando que se dispunha a ensinar tanto a ricos como a pobres, com o objetivo de neles, fazer brotar a luz da razão, da crítica, levando-os a aprender a pensar por conta própria, por meio de seu método interrogativo. De modo análogo, seu discípulo Platão assume a responsabilidade de conduzir seus ouvintes a estabelecerem em si mesmos o compromisso do confronto direto entre a razão e a verdade.

Embora a concepção platônica considere o aspecto político como a mais elevada aspiração destinada ao homem, tanto que, Marrou declara que "Platão versa menos o problema geral da formação do cidadão que o da formação do técnico, do perito em assuntos políticos" (MARROU, 1975, p. 109), Platão ultrapassa essa vocação estritamente política e edifica "o seu sistema educacional ${ }^{4}$ sobre a noção fundamental da verdade, sobre a conquista da verdade pela ciência racional" (MARROU, 1975, p. 110), uma ciência autêntica e verdadeira, fundamentada na razão, oposta ao senso comum, ciência esta que "qualificará, também aquele que, ao invés de uma cidade, tem apenas sua família e sua casa para reger" (MARROU, 1975, p. 110). Nesse sentido, podemos inferir que a educação do aprendiz não termina quando este deixa a presença do mestre, mas, é justamente nesse ponto que ela começa, quando ele passa a exercer seu papel de cidadão vivendo em comunidade, participando na vida pública, e, "se vê forçado a conhecer as leis e a viver de acordo com o seu modelo e exemplo" (JAEGER, 1994, p. 361), ele passa a viver de forma autônoma, a ser governado pela sua própria razão, pelo conhecimento e pela busca consciente e responsável do saber.

O ideal filosófico e educacional grego, Paidéia, foi posteriormente absorvido e desenvolvido pelo império Romano, agora com o nome de Humanitas, que se relaciona ao aspecto humanístico da educação e formação humana. O desenvolvimento de Roma agregou ao seu ideal pedagógico novas concepções educacionais com a incorporação da Igreja

\footnotetext{
4 Lembramos mais uma vez que o objetivo da educação platônica não se dirigia às massas ou à população em geral, antes, visava à formação do filósofo, do pensador, futuro estadista, pessoas distintas que representavam o público alvo da sua "Academia" em Atenas.
} 
pelo Estado. Segundo Gadotti, por conta disso, os romanos conseguiram universalizar a sua Humanitas e, "todas as cidades e regiões conquistadas eram submetidas aos mesmos hábitos e costumes" (GADOTTI, 2002, p. 44), é o que se chama de "romanização".

Durante toda a Idade Média, as concepções pedagógicas se relacionavam com aquelas que eram defendidas e impostas pela ordem religiosa. A Escolástica ${ }^{5}$ estruturava-se a partir da racionalização da fé, e "da educação escolástica medieval à educação humanística do Renascimento, o eixo central da formação havia se direcionado da teologia para as letras" (BRAGA, 2000, p. 50), os textos de caráter religiosos começam a ceder lugar à literatura clássica, mas, é somente no período do Iluminismo que as grandes mudanças educacionais voltaram a ser pensadas e discutidas, na direção de se "recriar uma nova sociedade a partir de um novo ideal de cultura" (BRAGA, 2000, p. 50). Enquanto o ideal grego era centrado na filosofia, o ideal iluminista se orienta pela ciência: "o novo racionalismo científico passa a ser pensado como fundamento para a expansão das idéias da ilustração. Nessa linha, todo o conhecimento humano deveria ser reordenado a partir de um novo referencial" (BRAGA, 2000, p. 51)

Passamos agora a analisar e a discutir a autonomia no contexto da idade moderna. É evidente que o conceito de autonomia no período clássico não está circunscrito às reflexões que apresentamos, contudo, em se tratando de um artigo, o espaço é infuciente para o desenvolvimento

\footnotetext{
5 Segundo Abbagnano, a Escolástica refere-se à filosofia cristã da Idade Média, mais precisamente no tocante à atividade educacional, era a filosofia da escola. "O problema fundamental da Escolástica é levar o homem a compreender a verdade revelada (...). A Escolástica, portanto, não é uma filosofia autônoma, como a filosofia grega: seu dado ou sua limitação é o ensinamento religioso, o dogma" (ABBAGNANO, 1997, p. 344).

6 Evidente que há muitas variáveis nessas generalizações, no entanto, o que se pretende aqui é evidenciar os grandes blocos na busca do conceito de autonomia. É preciso ressaltar ainda que cada autor de cada período histórico recebeu influências específicas e dialogou com os seus interlocutores, então, para o cuidadoso estudo da Idade Média, por exemplo, por certo faria sentido entrar nos aspectos que diferem um autor de outro e mesmo de um momento de outro, ao longo de um mesmo século, ou ainda durante um curto espaço de tempo. Esta observação é importante para que o leitor compreenda que este trabalho não pretende esquadrinhar todos os períodos históricos e suas respectivas concepções educacionais, mas, a partir de alguns deles, reunir e construir elementos para a compreensão da concepção de autonomia que se tinha na sua determinada época.
} 
mais cuidadoso das variáveis que envolvem a autonomia neste período histórico, mesmo assim, assumimos os riscos das incorreções cometidas com o cuidado de assumir que a vertente da Paidéia não é a única forma de perceber a autonomia neste período. A dimensão política tem forte marca, em especial com Aristóteles, no entanto, não se trata do foco dessas investigações. A análise da autonomia na modernidade também não será feita de forma aprofundada considerando as diferentes influências deste importante período para os tempos atuais, então, o propósito de apresentar um recorte que dê conta das principais questões inseridas no século das luzes parece justificar a acepção daquilo que vai influenciar diversas correntes pedagógicas da atualidade; afinal, o espírito moderno de educação, de cultura e de política ainda vigora no ocidente de forma majoritária.

\section{A autonomia do aluno na Idade Moderna - a concepção iluminista de educação}

O Iluminismo marcou por excelência o século da educação. Movimentos populares que buscavam mais acesso à educação se espalharam, promovendo reorganizações pedagógicas em várias partes da Europa, apoiadas em teorias fundamentadas no homem como o objetivo e o centro dos esforços educativos. $\mathrm{O}$ antigo modelo tradicional passa a ser severamente criticado, abrindo espaço, não mais para a transmissão de um conhecimento estático e dogmático, mas para o exercício sistemático da razão, onde a construção do conhecimento e a experiência pessoal passam a ser os alvos dos novos modelos pedagógicos.

Dentre as principais figuras do período, destacamos Jean-Jacques Rousseau como um marco entre a velha e a nova educação. Seu livro, o Emílio ou Da educação, é por muitos ${ }^{7}$ considerado o primeiro grande tratado da pedagogia moderna, constituindo-se de fonte para muitos outros pensadores - dentre os quais destacaremos posteriormente Immanuel Kant. Entretanto, o próprio Rousseau atribui esta honra a Platão, em sua obra $A$

\footnotetext{
7 Recomendamos a recente obra publicada pela Autêntica, Kant \& a Educação, de Claudio Dalbosco (2011), que diz respeito ao estudo sistemático das correlações de Kant e a educação. Trata-se de um estudo primoroso que não se limita à análise de Sobre a Pedagogia do filósofo de Könisberg, mas, perpassa seus principais trabalhos. Além desta obra, Dalbosco publicou também outra obra em 2011, intitulada Educação natural em Rousseau.
} 
República: "Não se trata de uma obra de política, como pensam os que julgam os livros pelos títulos: é o mais belo tratado de educação que jamais se escreveu" (ROUSSEAU, 1968, p. 14).

Rousseau procura em sua obra estabelecer uma nova visão educacional, a partir da vida concreta, da condição humana, atribuindo à natureza ${ }^{8}$ papel essencial para a sua formação. Afirma que "a verdadeira educação consiste menos em preceitos do que em exercícios" (ROUSSEAU, 1968, p. 16), criticando dessa forma o ensino tradicional que atribui maior valor à apreensão estática das 'verdades' históricas socialmente produzidas que à experiência do educando, afirmando que o educador "não deve dar preceitos, deve fazer com que os encontrem" (ROUSSEAU, 1968, p. 28).

A construção do livro, em torno de uma ficção com base na relação entre o Rousseau professor e seu discípulo infante, Emílio aponta para a meta que pretende alcançar nesse novo cenário educacional que propõe. A educação da criança, centrada na criança, partindo de suas necessidades específicas e características inatas, até a formação do homem 'humanizado': "Homens, sejais humanos, é vosso primeiro dever (...). Amai a infância; favorecei seus jogos, seus prazeres, seu amável instinto" (ROUSSEAU, 1968, p. 61).

Segundo Gadotti, Rousseau "centraliza, pela primeira vez, o tema da infância na educação. A partir dele, a criança não seria mais considerada um adulto em miniatura: ela vive em um mundo próprio que é preciso compreender" (GADOTTI, 2002, p. 87). Rousseau insiste que a educação precisa ser centrada na criança, e é a partir dela que se deve pensar o ato educacional, este deve seguir o seu ritmo e atender às suas necessidades; criticando dessa forma o sistema paradigmático da educação tradicional, afirmando que "nossa mania pedante de educar é sempre a de ensinar às crianças o que aprenderiam muito melhor sozinhas e esquecer o que somente nós lhes poderíamos ensinar" (ROUSSEAU, 1968, p. 59), acusando assim, uma inversão de valores que poderia vir a empobrecer a função educacional, que, para ele, é a de fornecer ao homem: "tudo o que não temos ao nascer, e de que precisamos adultos" (ROUSSEAU, 1968, p. 10).

8 Rousseau, inspirado em observações sobre a natureza, a considera o primeiro grande professor do homem, afirmando que "ao nascer, a criança já é discípulo, não do governante e sim da natureza. O governante não faz senão estudar, orientado por esse primeiro mestre" (ROUSSEAU, 1968, p. 40) - o governante, nesse sentido, refere-se ao educador infantil. 
A finalidade suprema da educação, segundo Rousseau, é a formação do homem para a vida, no que se refere ao caráter, à moralidade, enfim à humanidade:

$\mathrm{Na}$ ordem natural, sendo os homens todos iguais, sua vocação comum é o estado de homem; e quem quer seja bem educado para esse, não pode desempenhar-se mal dos que com esse de relacionam. Que se destine meu aluno à carreira militar, à eclesiástica ou à advocacia pouco me importa. Antes da vocação dos pais, a natureza chama-o para a vida humana. Viver é o ofício que quero lhe ensinar. Saindo de minhas mãos, ele não será, concordo, nem magistrado, nem soldado, nem padre; será primeiramente um homem. Tudo o que um homem deve ser, ele o saberá, se necessário, tão bem quanto quem quer que seja; e por mais que o destino o faça mudar de situação, ele estará sempre em seu lugar (ROUSSEAU, 1968, p. 15).

Ainda nessa direção, Rousseau afirma que "há somente uma ciência a ensinar às crianças: é a dos deveres de homem" (ROUSSEAU, 1968, p. 28). Embora Rousseau insista para que se trate a criança como criança, determina que a finalidade da educação seja a de transformá-la em homem. Para isso, procura, por meio de máximas, orientar o seu leitor tanto da sua necessidade quanto da sua eficiência nesse propósito, sem perder a direção de que "o espírito dessas regras está em conceder às crianças mais liberdade e menos voluntariedade, em deixá-las com que façam mais por si mesmas e exijam menos dos outros" (ROUSSEAU, 1968, p. 50), ou seja, Rousseau propõe que as crianças se desenvolvam com autonomia, utilizando-se da sua liberdade para a promoção do desenvolvimento pessoal.

Nesta obra, segundo Morandi, Rousseau também aponta novas perspectivas ao papel docente, desafiando os antigos modelos e propondo uma nova forma para pensar a educação e o desenvolvimento infantil:

O professor tem de deixar a criança desenvolver sua "natureza", dirigi-la sem autoridade evidente, instruí-la no contato casual das coisas. Ele deve levá-la a descobrir o que lhe é útil perseguir, a se exercitar espontaneamente, a aprender a bastar a si mesmo; estimulá- 
la a não depender dos livros, a ter a própria opinião, sem recorrer ao julgamento do outro; ajudá-la a tornar-se adulta gradualmente, primeiro pelo corpo, depois pelo espírito. Apesar de Émile e seu mestre serem personagens fictícios, essa orientação da atividade do mestre voltada para o aprendiz é um momento fundamental para a pedagogia (MORANDI, 2008, p. 40).

Rousseau (1968) apresenta uma proposta pedagógica libertadora, que destaca a responsabilidade da criança, promovendo sua autonomia. A nova concepção de sociedade, instaurada pelo Iluminismo, requer indivíduos mais participativos, e, nesse sentido, o objetivo da educação é o de elevar os homens, humanizando-os e tornando-os independentes por meio do exercício da razão, ou, como propõe Kant (2008), tornando-os esclarecidos.

Inspirado pela obra de Rousseau, Kant em seu texto Sobre a pedagogia ${ }^{9}$, atribui diretamente a cada pessoa a responsabilidade pela sua educação, dizendo que "o homem não pode tornar-se um verdadeiro homem senão pela educação. Ele é aquilo que a educação dele faz" (KANT, 1996, p. 15).

A educação, para Kant (1996), caracteriza-se a partir de duas fases: a dos cuidados com a infância e, posteriormente, a da formação propriamente dita, desenvolvida por meio da instrução, que visa, além de tornar o homem culto, prudente e moralizado, desenvolver a disciplina ${ }^{10}$ pessoal. Dentre os objetivos dessa educação, Kant (1996) confere destaque à disciplina, que, paradoxalmente tem por finalidade libertar o homem,

9 O texto de Kant (1996) Sobre a pedagogia, intimamente inspirado pela obra de Rousseau é, na verdade uma compilação de uma série de palestras que ministrou nos anos de 1776/77, 1783/84 e 1786/87 na Universidade de Königsberg, publicado posteriormente por seu discípulo Theodor Rink.

${ }^{10}$ Para Kant, "a disciplina é o que impede ao homem de desviar-se do seu destino, de desviar-se da humanidade, através das suas inclinações animais (...), é o tratamento através do qual se tira do homem a sua selvageria (...), a disciplina submete os homem às leis da humanidade" (KANT, 1996, p. 12). Entretanto, é importante ressaltar que o autor deixa claro que "é preciso cuidar para que a disciplina não trate as crianças como escravos, mas sim que faça que elas sintam sempre sua liberdade" (KANT, 1996, p. 12), liberdade para querer algo e conseguir levar a termo, e não sendo obstruídas pela sua própria fraqueza moral, por exemplo. 
impedindo que ele venha a se prejudicar, produzindo barreiras na busca pelo seu aperfeiçoamento individual e, a partir dela, situa: o desenvolvimento da cultura escolástica ou mecânica, por meio da aprendizagem de habilidades específicas como o ler e o escrever e as demais informações que visam torná-lo culto e instruído sobre os conhecimentos gerais; a prudência, que, para o filósofo, é uma capacidade que se relaciona à boa convivência social, à civilidade do homem e, por fim à moralização, que implica em uma disposição pessoal para a escolha do bem em detrimento do mal.

Essa formação humana (Bildung) ${ }^{11}$, mencionada no parágrafo anterior, pode, para Kant, (1996) ser alcançada pelo treinamento, pela instrução oferecida mecanicamente ou, o que considera mais desejável, pela ilustração ${ }^{12}$. Dessa maneira, o filósofo de Königsberg insiste que "não é suficiente treinar as crianças; urge que aprendam a pensar. Devem-se observar os princípios dos quais todas as ações derivam" (KANT, 1996, p. 28), chama a atenção para a relação entre causa e consequência. Notemos também que, para o filósofo, pensar é, pois, uma atividade que precisa ser aprendida e exercitada.

O que Kant propõe é o uso da razão para o benefício próprio, pois afirma que "o homem tem necessidade de sua própria razão" (KANT, 1996, p. 12). O próprio Rousseau, da mesma forma, afirma que "somente a razão nos ensina a conhecer o bem e o mal” (ROUSSEAU, 1968, p. 48). Assim, a razão se constitui em elemento essencial para o desenvolvimento do educando, promovendo e satisfazendo sua curiosidade natural e a sua demanda pelo conhecimento novo.

\footnotetext{
${ }^{11}$ Bildung: palavra alemã que significa cultivo do homem ou, 'cultivo de si' e designa o ideal de formação educacional e cultural humano da Alemanha do século XIX, relacionase, portanto ao ideal pedagógico formativo para o homem. Segundo Abbagnano, a formação "indica o processo de educação ou de civilização, que se expressa nas duas significações de cultura, entendida como educação e como sistema de valores simbólicos" (ABBAGNANO, 2007, p. 470). Para Weber "não seria exagerado afirmar que Bildung é um dos termos/ conceitos mais importantes da língua alemã" (WEBER, 2011, p. 49) e, se vincula ao "movimento de 'tornar-se o que se é', ou seja, ao movimento de constituição da própria identidade" (WEBER, 2011, p. 50), abrangendo assim, a totalidade da formação humana.

${ }^{12}$ A palavra ilustração, nesse sentido, representa algo passível de ser obtido, alcançado pela da luz da razão, pelo esclarecimento, uma atitude de busca e interesse pessoal, referência direta ao Século das Luzes, ao Iluminismo.
} 
O aprendiz assume, nesse sentido, maior responsabilidade por sua formação, devendo esforçar-se na direção de favorecer o seu próprio desenvolvimento. Em outro texto, Resposta à pergunta: o que é o esclarecimento?, Kant (2008) explica que quando o homem se acostuma a depender de alguém que pense por ele e lhe diz o que, como e quando algo deve ser feito, já não se esforça para romper essa condição, pois lhe parece mais cômodo e seguro. O filósofo também alerta sobre as dificuldades da jornada emancipatória e considera que a preguiça e a covardia são as causas pelas quais muitos se comprazem em permanecer na situação de minoridade, de forma que são raros os que conseguem, com responsabilidade e confiança, libertarem-se dessa condição, pois, como afirma, isso "não resulta da falta de entendimento, mas da falta de resolução e de coragem necessárias para utilizar seu entendimento sem a tutela de outro" (KANT, 2008, p. 11), afinal, é "cômodo ser menor" (KANT, 2008, p. 12). A essência da autonomia educacional iluminista consiste, portanto, no exercício crítico da razão.

Esse novo ideal formativo assume características políticas e alcança setores da sociedade antes esquecidos. A instrução passa a ser considerada como direito da nação. "A instrução é ao mesmo tempo uma ordem de saber (as luzes das ciências) e uma ordem política (a cidadania)" (MORANDI, 2008, p. 41). É preciso notar que a palavra aqui utilizada é instrução e não educação. "Trata-se do princípio da laicidade, como exigência racional e modo de preservação da educação privada" (MORANDI, 2008, p. 41). Nesse contexto, a ação das instituições públicas de ensino é limitada à instrução, cabendo à família o papel educacional.

Muitos outros modelos pedagógicos desenvolveram-se a partir da base iluminista, alcançando nossos dias, conduzindo em seu íntimo os elementos essenciais da pedagogia moderna questionados primeiramente por pensadores como Rousseau e Kant.

Se retomarmos a formulação da pergunta deste artigo, isto é, como as acepções do termo autonomia foram discutidas nos períodos clássico e moderno?, talvez tenhamos algumas pistas que serão sistematizadas nas considerações finais. 


\section{Considerações finais}

Ao longo dessas reflexões, procuramos mostrar os vínculos do conceito de autonomia nos períodos clássico e moderno. Alertamos para o caráter abrangente da temática do artigo e justificamos o recorte desses dois momentos com razões que dizem respeito à nossa necessidade de ressignificação do conceito de autonomia na atualidade; afinal, é preciso dar condições efetivas para que os estudantes possam desenvolver a autonomia para a vida, para a conquista de sua cidadania.

Se a retomada da Paidéia forneceu elementos para a percepção de que a educação devia se fazer a partir de virtudes e, por outro lado, se a figura de Sócrates representou este ideal de homem, inclusive em contraposição aos sofistas, então, a primeira consideração do artigo em relação às acepções de autonomia ao longo da história do pensamento diz respeito à necessidade de se inserir a educação como condição de mudança da percepção da vida do homem. A educação grega não diz respeito a uma educação instrumental e utilitalista; antes, significa, sobretudo, a formação do caráter do homem, logo, a autonomia é a condição para o desenvolvimento desta disposição humana na busca da verdade.

Se a modernidade, especialmente o século XVII, diz respeito à ressignificação educacional que insere o homem no seu centro, então, as figuras de Rosseau e Kant evidenciam importantes contribuições para a meta da educação racional. Neste sentido, se o ensino era enciclopédico na escolástica e se havia a necessidade de um novo centro para o desenvolvimento da educação, então, este centro foi o próprio homem e a educação passou se ocupar da experiência humana como leitmotiv da conquista do esclarecimento. A acepção educacional moderna, neste sentido, diferentemente da Paidéia que tinha a busca da verdade e o desenvolvimento de virtudes, é marcada pelo uso da razão. Não uma razão instrumental, mas a razão que ilumina, a razão que esclarece, a razão que tira o homem do estado de minoridade. Logo, a acepção educacional moderna prioriza a autonomia na conquista da liberdade.

As concepções grega e iluminista de educação, em destaque neste artigo, configuram-se por excelência como métodos promotores de autonomia nos alunos, e, em oposição ao método tradicional, compreendido 
aqui como o enciclopédico da Escolástica que tinha foco na memorização, incentivam o uso da razão e do pensamento crítico, apoiados nas ciências e nos princípios gerais, para trabalhar na construção do conhecimento.

A autonomia é, portanto, o elemento chave que faz a ligação entre o mundo da teoria presente na sala de aula e o da vida prática do cotidiano, talvez possamos dizer que a autonomia é o que dá à luz a prática educacional e, isso independentemente do momento histórico ou condição social em que se insere o sujeito educando.

\section{Referências}

ABBAGNANO, Nicola. Dicionário de filosofia. Tradução de Alfredo Bosi. Revisão de Ivone Castilho Benedetti. 5. ed. São Paulo: Martins Fontes, 2007.

BRAGA, Marco. A nova paidéia: ciência e educação na construção da modernidade. Rio de Janeiro: E-papers, 2000.

DALBOSCO, Claudio A. Kant \& a Educação. Belo Horizonte: Autêntica, 2011.

. Educação natural em Rousseau - das necessidades da criança e dos cuidados do adulto. São Paulo: Cortez, 2011.

FERREIRA, Aurélio Buarque de Holanda. Mini Aurélio: o dicionário da língua portuguesa. 8. ed. Curitiba: Positivo, 2010.

GADOTTI, Moacir. História das idéias pedagógicas. 8. ed. São Paulo: Ática, 2002.

JAEGER, Werner Wilhelm. Paidéia: a formação do homem grego. Tradução de Artur M. Parreira, adaptação para a edição brasileira Monica Stahel, revisão do texto grego Gilson Cesar Cardoso de Souza. 3. ed. São Paulo: Martins Fontes, 1994.

KANT, Immanuel. Resposta à pergunta: o que é o esclarecimento? Tradução de Luiz Paulo Rouanet. Brasília: Casa das musas, 2008.

. Sobre a pedagogia. Tradução de Francisco Cock Fontanella. Piracicaba: Unimep, 1996. 
KOHAN, Walter Omar. Sócrates \& a Educação: o enigma da filosofia. Tradução de Ingrid Müller Xavier. Belo Horizonte: Autêntica, 2011.

MARROU, Henri Irénée. História da educação na antiguidade. Tradução de Mário Leônidas Casanova. São Paulo: EPU, 1975.

MÄRZ, Fritz. Grandes educadores: perfis de grandes educadores e pensadores pedagógicos. Tradução de Edwino A. Royer. São Paulo: EPU, 1987.

MORANDI, Franc. Introdução à pedagogia. São Paulo: Ática, 2008.

PLATÃO. Apologia de Sócrates. Tradução de Enrico Corvisieri. In: . Sócrates: vida e obra. Coleção Os Pensadores. São Paulo: Nova Cultural, 1999.

ROUSSEAU, Jean-Jacques. Emílio ou da educação. 3.ed. São Paulo: Difel, 1979.

SAVIANI, Dermeval. História das idéias pedagógicas no Brasil. 2. ed. Campinas: Autores Associados, 2008.

WEBER, José Fernandes. Formação (Bildung), educação e experimentação em Nietzsche. Londrina: Eduel, 2011. 